\title{
HEALTH PASTORAL CARE
}

\author{
C.B. Kusmaryanto
}

\begin{abstract}
:
In her long history, the Churchalways gives special attention to the sick and sufferings, in order to be present in all human condition. Pastoral care is offered for the sick, especially for those who are in the terminal ill. Health Pastoral Care wants to emphasize this point. Health pastoral care is very important in health services, especially in the Catholic healthcare institution. It serves not only the patients and their family but also the entire healthcare personals. Their main role is providing religious and spiritual assistance. In the recent time, their role is even wider, including social and psychological assistance. The Church is very supportive to this pastoral care. Health Pastoral care is an integral part of the Church's mission to proclaim the Kingdom of God.
\end{abstract}

\section{Kata-kata Kunci:}

Health Pastoral Care, akhir hidup manusia, sakramen sakramen bagi orang sakit, pelayanan kesehatan, rumah sakit

\section{PENGANTAR}

Sudah sejak lama Gereja memandang pelayanan pastoral bagi orang yang sakit dan keluarganya itu sangat penting. Pelayanan Gereja bagi orang sakit itu ada banyak, misalnya: sakramen pengurapan orang sakit (sakramen minyak suci), Viaticum (komuni bekal suci), sakramen rekonsiliasi terakhir, kunjungan kepada orang sakit dsb. Orang yang akan meninggal (bahaya maut) mendapatkan tempat yang sangat istimewa dalam pandangan Gereja, bahkan ada beberapa halangan hukum yang bisa dihilangkan dalam keadaan darurat kematian. Semua karya pastoral ini dilakukan oleh Gereja dengan satu tujuan akhir yakni supaya mereka yang meninggal mendapatkan keselamatan abadi dan keluarga yang ditinggalkan mendapatkan kekuatan untuk menghadapi situasi yang sulit itu.
Tahap terakhir dari hidup seseorang di dunia ini sangat berarti karena bisa menentukan selamat atau tidak jiwanya. Kita ingat drama penyaliban Yesus dan bagaimana penjahat yang ada di sebelah kanan Yesus itu dalam Injil Lukas 23:42-43 "Lalu ia berkata: "Yesus, ingatlah akan aku, apabila Engkau datang sebagai Raja." Kata Yesus kepadanya: "Aku berkata kepadamu, sesungguhnya hari ini juga engkau akan ada bersama-sama dengan Aku di dalam Firdaus." Perikopa ini menunjukkan betapa pentingnya saat terakhir kehidupan manusia dalam tata keselamatan Allah. Orang bisa bertobat pada detik-detik akhir hidupnya sehingga ia bisa diselamatkan.

Dari segi institusional, pelayanan kepada mereka yang sakit juga mendapatkan tempat istimewa. Paus Yohanes Paulus II dengan Motu Proprio "Dolentium Hominum" tanggal 11 February 1985 mendirikan 
Pontifical Commission for the Pastoral Assistance to Health Care Workers, yang kemudian pada tahun 1988 diubah status dan namanya menjadi Pontifical Council for the Pastoral Assistance to Health Care Workers dengan diundangkannya dokumen Pastor Bonus oleh Yohanes Paulus II. Dalam lembaga ini, health pastoral care mendapatkan jatah perhatian yang istimewa. Dengan didirikannya lembaga ini, ingin digaris bawahi bahwa health pastoral care yang selama ini sudah dijalankan, mendapat tempat dan perhatian khusus di dalam Gereja.

Dalam Dolentium Hominum no. 1 dikatakan, "Perhatian Gereja yang sangat besar kepada orang yang menderita itu sudah terkenal. Dalam hal ini, Gereja hanya mengikuti contoh teladan dari Sang Guru dan Pendiri Gereja.” Pentingnya pastoral care ini juga ditekankan dalam nomor yang sama, "Sesungguhnya, selama berabadabad Gereja sudah sangat menekankan bahwa pelayanan kepada orang yang sakit dan menderita itu adalah bagian integral dari misi Gereja sehingga Gereja bukan hanya mendorong umat Kristiani untuk menumbuhkembangkan pelbagai macam karya belas kasih tetapi juga mendirikan banyak institusi religius di dalam Gereja dengan tujuan khusus membantu perkembangan, mengorganisir, meningkatkan dan menambah jumlah bantuan kepada saudara-saudari yang sakit. Pada gilirannya, dalam melaksanakan karya evangelisasinya banyak misionaris selalu mengkombinasikan antara pewartaan Injil dengan pelayanan kepada orang yang sakit."

\section{MISI PERUTUSAN YESUS}

Spiritualitas Kristiani bersumber kepada Kristus maka perlu menelusur Kristus itu sendiri. Menurut I Yohanes 4:8 "Allah adalah kasih". Allah begitu mengasihi manusia sehingga mengutus Anak-Nya yang tunggal ke dunia supaya setiap orang yang percaya kepada-Nya tidak binasa, melainkan beroleh hidup yang kekal, "Karena begitu besar kasih Allah akan dunia ini, sehingga Ia telah mengaruniakan Anak-Nya yang tunggal, supaya setiap orang yang percaya kepada-Nya tidak binasa, melainkan beroleh hidup yang kekal."(Yohanes 3: 16).
Itu dilakukan dengan mengakat manusia menjadi anak-anak Allah (I Yohanes 3:1; Roma 8:4. 16-17; Galasia 3: 26) sehingga hanya oleh karena cinta dan rahmatNyalah kita diselamatkan dan bukan pertama-tama oleh karena kekuatannya sendiri (Roma 3: 23-24).

Manusia menanggapi tawaran keselamatan dari Allah itu dengan beriman (DV 5). Iman itu harus dinyatakan dalam perbuatan agar iman itu menjadi iman yang hidup (Yakobus 2:14-18). Perbuatan manusia menjadi medan perwujudan iman yang sudah direngkuhnya. Oleh karena itu, perbuatan (pekerjaan) manusia itu seharusnya juga menjadi perlanjutan misi Kristus sendiri yakni untuk menyelamatkan dunia dan dengan demikian maka perbuatan manusia beriman mempunyai dimensi misi salvivic (penyelamatan). Agar terjadi keselasaran antara iman dan perbuatan maka manusia beriman harus menimba visi dan motivasi utama Yesus Kristus ketika datang ke dunia yakni pewartaan Kerajaan Allah yang berdasarkan cinta kasih. Pelayanan kesehatan pun juga memakai pola yang sama. Para pelayan kesehatan ingin mewujudkan imannya dalam pelayanan kesehatan yang sekaligus sebagai pewartaan Kerajaan Allah. Pelayanan kesehatan bukan hanya sarana untuk mencari nafkah, tetapi juga medan perwujudan iman, mewartakan Kerajaan Allah.

\section{PELAYAN KESEHATAN DAN RUMAH SAKIT KATOLIK SEBAGAI SARANA PEWARTA KERAJAAN ALLAH}

Yesus datang ke dunia untuk memberitakan Kerajaan Allah. Ia memakai banyak cara untuk mewartakan Kerajaan Allah itu, salah satu yang paling kentara ialah dengan cara menyembuhkan orang. "Yesus berkeliling ke semua kota dan desa; Ia mengajar dalam rumah-rumah ibadat dan memberitakan Injil Kerajaan Sorga serta melenyapkan segala penyakit dan kelemahan." (Matius 9:35). Juga bagian lain dari Mateus ditekankan bahwa "Yesus pun berkeliling di seluruh Galilea; Ia mengajar dalam rumahrumah ibadat dan memberitakan Injil Kerajaan Allah serta melenyapkan segala penyakit dan kelemahan di antara bangsa itu. Maka tersiarlah berita tentang Dia di 
seluruh Siria dan dibawalah kepada-Nya semua orang yang buruk keadaannya, yang menderita pelbagai penyakit dan sengsara, yang kerasukan, yang sakit ayan dan yang lumpuh, lalu Yesus menyembuhkan mereka." (Mateus 4:23-24)

Bagi Yesus, kesembuhan dari sakit itu menjadi tanda keselamatan (Kerajaan Allah) bagi orang yang disembuhkan. Oleh karena itu setiap kali terjadi penyembuhan fisik, aspek keselamatan itu sangat menonjol, "Teguhkanlah hatimu, hai anak-Ku, imanmu telah menyelamatkan engkau." Maka sejak saat itu sembuhlah perempuan itu." (Mateus 9:22). Kesembuhan itu terjadi dalam kerangka penyelamatan. Masih ada banyak nast Kitab Suci lain yang berbicara mengenai hubungan iman dengan penyembuhah, misalnya Markus 5:34, 10:52, Mateus 15:28, Lukas 7:50, 8:48, 17:19, 18:42 dsb. Bisa diringkaskan bahwa kalau Yesus menyembuhkan orang, pasti Dia buat dalam kerangka pewartaan Kerajaan Allah (keselamatan) Bahkan bisa dikatakan bahwa datangnya Kerajaan Allah terwujud nyata di dalam penyembuhan orang sakit.

Oleh karena Yesus mewartakan Kerajaan Allah melalui penyembuhan penyakit maka tidak mengherankan juga bahwa Ia memerintahkan para pengikutnya untuk menyembuhkan orang sakit, akan tetapi itupun dibuatnya selalu dalam kerangka pewartaan, misalnya: Matheus 10:7 - 8 "Pergilah dan beritakanlah: Kerajaan Sorga sudah dekat. Sembuhkanlah orang sakit; bangkitkanlah orang mati; tahirkanlah orang kusta; usirlah setan-setan." Dalam bagian lain dikatakan, "Dan jikalau kamu masuk ke dalam sebuah kota dan kamu diterima di situ, makanlah apa yang dihidangkan kepadamu, dan sembuhkanlah orang-orang sakit yang ada di situ dan katakanlah kepada mereka: Kerajaan Allah sudah dekat padamu." (Lukas 10:8-9).

Ternyata Yesus bukan hanya memerintahkan untuk menyembuhkan tetapi Ia juga memberikan kekuasaan dan tenaga kepada para murid untuk menyembuhkan orangorang sakit, "Yesus memanggil kedua belas murid-Nya dan memberi kuasa kepada mereka untuk mengusir roh-roh jahat dan untuk melenyapkan segala penyakit dan segala kelemahan." (Mateus 10:1). Juga dikatakan, "Maka Yesus memanggil kedua belas murid-Nya, lalu memberi-kan tenaga dan kuasa kepada mereka untuk menguasai setan-setan dan untuk menyembuhkan penyakit-penyakit." (Lukas 9:1). Yesus menyatakan bahwa kemampuan untuk menyembuhkan itu adalah bukti kebenaran Injili yang mereka buat, "Tanda-tanda ini akan menyertai orang-orang yang percaya: mereka akan mengusir setan-setan demi nama-Ku... mereka akan meletakkan tangannya atas orang sakit, dan orang itu akan sembuh." (Markus 16: 17-18).

Oleh karena diperintahkan oleh Yesus untuk menyembuhkan dalam kerangka pewartaan Kerajaan Allah, maka para murid pertama pun melakukan hal yang sama, "Tetapi Petrus berkata: "Emas dan perak tidak ada padaku, tetapi apa yang kupunyai, kuberikan kepadamu: Demi nama Yesus Kristus, orang Nazaret itu, berjalanlah!" (Kisah Para Rasul 3:6) Demikian pula selanjutnya dalam Kisah Rasul 5:14-16 "mereka membawa orang-orang sakit ke luar, ke jalan raya, dan membaringkannya di atas balai-balai dan tilam, supaya, apabila Petrus lewat, setidak-tidaknya bayangannya mengenai salah seorang dari mereka. Dan juga orang banyak dari kota-kota di sekitar Yerusalem datang berduyun-duyun serta membawa orang-orang yang sakit dan orang-orang yang diganggu roh jahat. Dan mereka semua disembuhkan." Teks lain yang juga bicara mengenai penyembuhan yang dilakukan oleh para murid, misalnya Kisah Rasul 3,1-10; 8,7; 9,33-35; 14,8-10; 28,8-9. Dari teks-teks itu kita bisa menarik kesimpulan bahwa dalam Gereja Perdana, para murid mewartakan Kerajaan Allah dengan cara melakukan banyak penyembuhan oleh karena diperintahkan dan diberi kuasa oleh Yesus.

Dalam perkembangan Gereja selanjutnya, trend seperti itu tetap dilanjutkan. Banyak terjadi mujizat penyembuhan dari orang-orang kudus. Mujizat penyembuhan orang sakit dgn perantaraan seorang yang sudah meninggal menjadi tanda bahwa orang yang telah meninggal berada dalam keselamatan Allah. Salah satu syarat pengakuan sebagai orang kudus (baik beata 
ataupun santa/o) adalah adanya mujizat dan mujizat yang paling banyak terjadi ialah penyembuhan.

Ketika terjadi perubahan zaman dimana dituntut profesionalitas dari seorang penyembuh maka penyembuh perlu pendidikan khusus supaya mempunyai kompetensi dan keahlian yang memadai agar lahirlah dokter dan pelayan kesehatan lainnya yang mumpuni. Akan tetapi, apa yang ada di dalamnya tidak berubah, yakni spiritualitasnya.

Para pelayan kesehatan Katolik selayaknya mengikuti jejak Kristus. Sebagaimana Yesus mewartakan Kerajaan Allah melalui karya-karya penyembuhan, demikian juga para pelayan kesehatan seharusnya menghayati pekerjaan penyembuhannya sebagai sarana pewartaan Kerajaan Allah. Yesus sebagai Tabib Ilahi menjadi pendorong yang menggerakkan seorang pelayan kesehatan untuk berbuat menolong sesamanya yang sedang sakit.

Sebagai anggota Gereja, para pelayan kesehatan dalam banyak kesempatan diteguhkan oleh ajaran magisterium mengenai fungsi dan martabatnya dalam misi Gereja. Magisterium gereja selalu menekankan bahwa pelayanan kepada mereka yang sakit menjadi bagian integral dari pelayanan gereja yang tidak bisa dipisahkan dari pelayanan yang lain. "Gereja yg memandang pelayanan kepada orang sakit sebagai bagian integral dari misinya memandangnya sebagai perwujudan dari pelayanannya." Dalam kesempatan lain dikatakan, "Setiap bentuk perhatian kepada orang yang sakit dan menderita adalah bagian hidup dan misi Gereja."2

Sepanjang sejarah Gereja, sudah banyak anggota Gereja yang menyediakan diri dengan sukarela untuk tugas pelayanan kesehatan ini, "Merelakan dirinya untuk dipimpin oleh teladan Yesus mengenai Orang Samaria yang baik hati itu (bdk. Lk 10:29-37) dan juga dikuatkan oleh dayaNya, Gereja selalu berada di garis terdepan untuk memberikan bantuan-bantuan karitatif: sudah ada begitu banyak putraputri Gereja, khususnya para biarawan dan biarawati, baik dalam bentuk-bentuk tradisional maupun dalam bentuk yang baru, yang telah dan akan selalu mengabdikan hidupnya bagi Allah, dengan bebas memberikan dirinya oleh karena cinta kepada sesamanya, khususnya bagi mereka yang lemah dan berkekurangan."

Dalam Charter for Healthcare Workers no. 5 dikatakan, "Perlu ditekankan bahwa pelayanan penyembuhan yang dilakukan oleh para pelayan kesehatan adalah sharing di dalam karya pastoral Gereja ${ }^{4}$ dan karya evangelisasinya ${ }^{5}$. Pelayanan kepada kehidupan menjadi pelayanan penyelamatan, yakni pesan yang mengaktifkan kasih Kristus yang menyebus manusia. Para dokter, perawat dan pelayan kesehatan yang lainnya, para voluntir lainnya, semuanya dipanggil untuk menjadi gambar yang hidup dari Kristus dan gerejaNya dalam mencintai orang yang sakit dan menderita: ${ }^{6}$ menjadi saksi 'Injil Kehidupan'.”7

\section{HEALTH PASTORAL CARE}

\section{Pengertian}

Health Pastoral Care dilihat langsung dari kata-katanya sudah menunjukkan apa yang dimaksudkan. Kata ini terdiri atas 3 kata, yakni "health" = kesehatan; "pastoral" $($ kata sifat $)=$ kegembalaan; "care" = merawat, memperhatikan, mengasuh, mengurus.

Patut dicatat beberapa hal berikut ini:

- Pastoral (kata sifat) yang berarti kegembalaan. Kata ini berasal dari kata pastor (kata benda) = gembala. Tujuan pastoral (kegembalaan) adalah untuk membantu orang menghayati iman dan untuk mendampingi orang $\rightarrow$ (cura animarum).

- Care = kata ini dalam bahasa Inggris kaya makna yang bukan hanya sekedar merawat tetapi juga memperhatikan, mengasuh dan mengurus dan juga ada nada untuk membantu (pasien) agar bisa berkembang dan agar bisa mengaktualkan dirinya sendiri sehingga bisa mandiri.

- $\quad$ Health $=$ kesehatan yang tentu saja jauh lebih luas dari pada kedokteran karena mencakup pelbagai aspek 
manusia yang sehat baik jasmani maupun rohani.

Pastoral care berbeda dengan konseling pastoral yang di dalamnya seorang konselor memberikan nasehat dan kiat-kiat tertentu kepada konseli agar bisa mengambil keputusan sendiri. Dalam hal ini, konselor tidak mengerjakan sesuatu kecuali hanya memberi nasehat. Dalam health pastoral care, pelaku dan yang mengerjakan pekerjaan itu adalah orang yang sama sehingga unsur bekerja di dalamnya menjadi sangat penting. Konseling pastoral menjadi bagian yang tak terpisahkan dari health pastoral care.

\section{Dimensi Pelayanan Kelembagaan}

Pastoral kegembalaan secara institusional bertujuan pokok agar seluruh kegiatan yang ada di rumah sakit tertuju kepada kegembalaan (membantu penghayatan iman dan pendampingan) terutama kepada mereka yang sakit dankeluarganya. Cakupan pastoral ini menyangkut banyak hal tergantung kepada keadaan lembaga Rumah Sakit -dengan tujuan pokok agar Rumah Sakit menjadi sarana pewartaan iman.

Pentingnya Pastoral Care bisa dilihat dalam dokumen Charter for Healthcare Workers no 108, "Pastoral care untuk orang sakit terdiri atas bantuan spiritual dan bantuan religius. Ini adalah hak fundamental dari pasien dan sekaligus kewajiban bagi Gereja (bdk. Mateus 10: 8, Lukas 9:2, 10:9) Kalau kita tidak menjamin pelaksanaannya, tidak mendukungnya, membuatnya sedemikian rupa sehingga menjadi tidak bebas memilih atau menghalanginya, maka kita melanggar hak ini dan kita tidak setia kepada tugas ini." Dalam Dolentium Hominum no 2 juga ditekankan pentingnya pastoral care ini, "Oleh karena itu, sangatlah mudah untuk mengerti betapa pentingnya pastoral care ini, dalam kerangka pelayanan kesehatan-sosial pada jaman sekarang: bukan hanya gembala jiwa tetapi juga pelayan-pelayan yang mempunyai pandangan integral sekaligus manusiawi mengenai sakit, yang konsekuensinya mempunyai pendekatan yang benar-benar manusiawi kepada manusia yang sedang sakit dan yang sedang menderita. Bagi orang-orang Kristiani, penebusan Kristus dan rahmat penyelamatannya merengkuh manusia secara utuh dalam kondisi manusiawinya dan oleh karena itu juga merengkuh juga sakit, penderitaan dan kematian.”

Dalam ensiklik Evangelium Vitae no. 30, Yohanes Paulus II menegaskan, "Pastoral Care ini adalah ugas yang sangat penting dan khusus -walaupun bukanlah hal yang ekslusif- bagi para petugas health pastoral care. Oleh karena pentingnya interaksi antara berbagai dimensi dalam diri manusia yakni fisik, psikologis dan spiritual dan oleh karena adanya tugas untuk memberikan kesaksian imannya, maka semua tenaga kesehatan terikat pada kewajiban untuk menciptakan kondisi agar bantuan religius dapat diterapkan bagi semua orang yang memintanya baik secara langsung maupun tidak langsung. Dalam Yesus yang adalah Sabda Kehidupan, hidup Allah yang kekal haruslah diwartakan dan diberikan. Kita bersyukur atas pewartaan dan anugerah ini maka hidup spiritual dan jasmani kita - juga dalam hidup kita di dunia ini mendapatkan makna dan arti yang penuh, oleh karena hidup kekal yang diberikan Allah menjadi arah dan tujuan kepadanya hidup kita ini harus diarahkan."

Dalam sambutannya, Paus Yohanes Paulus II mengatakan, "Pengalaman menunjukkan bahwa manusia ketika membutuhkan bantuan baik preventif maupun terapeutik ternyata membutuhkannya jauh melebihi kebutuhan patologis organis. Dia ternyata membutuhkan bukan hanya treatment yang cocok tetapi juga bantuan manusiawi sebagai saudara yang bisa berbagi keadaan dengannya. Bantuan medis yang dibutuhkan itu berasal dari semua tenaga medis yang pada suatu titik akan menjadi tidak banyak berguna namun bantuan dukungan sebagai saudara dalam keadaan sakit dan menderita itu tetap dibutuhkan. Apabila ini di dapat dalam iman, jawaban yang menenteramkan ini akan berhubungan dengan jawaban akan pertanyaan yang paling tinggi mengenai eksistensi manusia." (Johannes Paulus II, To the World Congress of Catholic Doctors, Oct. 3, 1982, dalam Insegnamenti V/3, p. 675, n. 6). 
Peran dari para petugas health pastoral care, terutama dalam saat akhir hidup manusia, menjadi sangat penting sehingga health pastoral care pada akhir hidup manusia mempunyai tempat yang sangat istimewa,

\begin{abstract}
"Seseorang yang berada dekat dengan dia yang sedang mengalami pencobaan besar yang disebabkan oleh penderitaan daging, bisa mempunyai pengaruh dan membentuk hidup rohaninya. Kehadiran pelayan kesehatan yang sudah dilatih dan dipersiapkan dengan baik, sangat penting, ketika manusia berjumpa dengan dirinya sendiri pada saat yang otentik dan nyata. Pelayan kesehatan ini 'harus dibimbing oleh visi kemanusiaan yang integral mengenai sakit dan oleh karena itu harus mengetahui bagaimana harus menghadapi dan mendekati orang yang sakit yang adalah manusia dalam arti sesungguhnya. Bagi orang Kristiani, penebusan Kristus dan rahmat penyelamatanNya merengkuh manusia secara keseluruhan dalam keseluruhan kemanusiawiannya, dan oleh karena itu juga menyangkut sakit, penderitaan dan kematiannya." (Dolentium Hominum, no. 2)
\end{abstract}

Di sinilah pewartaan menjadi sangat penting dalam health pastroral care. Yang dimaksud dengan bantual spiritual ialah kehadiran dan aktivitas Gereja yang dimaksudkan untuk menghadirkan Sabda dan rahmat Allah bagi mereka yang menderita dan bagi mereka yang merawatnya. Ini adalah bagian dari visi yang lebih luas dari bantuan pastoral medis. Dalam bantuan spiritual ini - imam, religius dan awam baik sebagai pribadi maupun kelompok yang bertugas untuk pastoral care bagi mereka yang sakit menghadirkan rahmat Allah bagi mereka yang menderita dengan cara pengudusan dan kasih yang dipercayakan kepada mereka. Tugas ini dilaksanakan dengan cara yang khusus." (no. 110)

Bantuan spiritual ini bisa berupa renungan, bacaan (perpustakaan), audio visual yang berguna untuk memperkuat pasien dan mendukung pasien untuk mengalahkan penyakit dan kesengsaraannya. Di sini kita mungkin bisa berbuat banyak dengan "radio rumah sakit" yang secara terprogram bisa mengudarakan program- program pilihan untuk pasien dan keluarganya.

Yang dimaksud bantuan religius ialah upacara-upacara keagamaan yang bermakna bagi yang sakit. Bagi gereja Katolik, ini berarti berupa sakramen pengurapan orang sakit, sakramen pengampunan dosa dan juga viaticum (komuni bekal suci).

Mengenai sakramen pengurapan orang sakit harus ditegaskan bahwa sakramen ini bukan hanya untuk mereka yang akan meninggal, tetapi untuk mereka yang kesehatannya terancam oleh penyakit dan usia tua. Yang boleh memberikan hanya imam dan boleh dirayakan baik secara pribadi maupun secara bersama-sama (umum). Sakramen ini bisa diberikan kepada orang sakit beberapa kali: bagi mereka yang pernah sakit dan kemudian sembuh lalu sakit lagi, maka mereka sebaiknya memenrima sakramen ini kembali. Juga bagi mereka yang dalam situasi sakit yang sama, tetapi sekarang penyakitnya semakin gawat, maka dalam situasi itu mereka juga sebaiknya menerima kembali. Sakramen ini juga bisa diberikan sebelum pasien mengalami operasi kalau dipandang bahwa operasi ini cukup serius. Sakramen ini juga bisa diberikan kepada para lansia jika mereka mengalami penrunan kekuatan walaupun mungkin tidak berada dalam bahaya mati. Juga bisa diberikan kepada anak, asal anak itu cukup bisa mempergunakan akal budinya. Sakramen ini tidak boleh diberikan kepada orang yang sudah jelas mati (nb. Dalam hal ini Gereja menyetujui kriteria kematian dengan ditandai kematian otak seluruhnya ataupun mati batang otak (MBO), Charter for Healthcare workers No. 112).

Sekali lagi: tugas health pastoral care ini merupakan konsekwensi logis dari penebusan kita manusia. Dengan penebusan, kita semua mendapatkan status sebagai imam, raja dan nabi. Imam untuk menyucikan, raja untuk memerintah dan nabi sebagai pewarta. Kita semua mengambil bagian dalam tugas dan karya Yesus sebagai mana diberitakan dalam Injil Lukas 4:18 "Roh Tuhan ada pada-Ku, oleh sebab Ia telah mengurapi Aku, untuk menyampaikan kabar baik kepada orang-orang miskin; dan Ia telah mengutus Aku untuk memberita- 
kan pembebasan kepada orang-orang tawanan, dan penglihatan bagi orang-orang buta, untuk membebaskan orang-orang yang tertindas, untuk memberitakan tahun rahmat Tuhan telah datang."

Ketika kematian semakin mendekat, maka kita juga memberikan bantuan spiritual dan religius yang diperlukan. Injil juga harus diwartakan kepada mereka yang akan meninggal melalui tindakan nyata. Charter for Healthacare no. 311 menyatakan bahwa semua umat beriman Kristiani mempunyai kewajiban untuk itu. Bagi petugas pastoral care, bantuan itu bukan hanya diberikan "di samping tempat tidur" oran yang akan meninggal tetapi juga pelayanan religius di sekitar kamar jenazah bagi orang tersebut dan juga bagi keluarganya baik melalui tindakan karitatif, doa dan sakramen-sakramen.

Dari sedikit keterangan di atas, menjadi jelaslah bagi kita bahwa health pastoral care bukan pekerjaan yang mudah dan murah dan sederhana. Pastoral care seharusnya menjadi mahkota pelayanan rumah sakit Katolik. Oleh karena tugas dan situasinya, para pelayan kesehatan kurang mampu untuk mewujudkan visi dan misi rumah sakit dimana mereka bekerja. Akibatnya, aspek pewartaan Kerajaan Allah dan perwujudan cinta kasih kepada sesama yang menderita ini kurang tampil ke depan sehingga kurang bisa dirasakan. Padahal inilah visi dan misi utama rumah sakit Katolik.

Untuk mengatasi kekurangan ini, maka pelayanan pastoral care menjadi sangat penting. Dalam kenyataannya di Indonesia, bidang ini sering kurang mendapatkan perhatian yang memadai. Sering orang yang ditugaskan untuk pastoral care adalah "tenaga sisa", misalnya para suster yang sudah tua dan tidak bisa bekerja di tempat lain, lalu ditempatkan di situ. Padahal inilah inti dari rumah sakit Katolik itu.

Oleh karena itu, salah satu program unggulan yang sebaiknya kita buat adalah pelayanan pastoral care yang baik. Pendampingan pastoral secara khusus bagi mereka yang sakit selalu dipandang sebagai bagian integral dari adanya rumah sakit Katolik. Mengapa? Karena pastoral care inilah yang paling kentara untuk mewujudnyatakan perutusan Gereja. Pastoral care adalah bagian integral dari pelayanan rumah sakit dimana orang mendapatkan bantuan pelayanan secara keseluruhan. Pelayanan ini sangat strategis dalam menghantar orangorang untuk berjumpa dengan Allah.

Dari peristiwa orang yang di salib di sebelah kanan Yesus kita bisa belajar bahwa bantuan yang diberikan kepada pendosa pada saat terakhir manfaatnya sangat luar biasa bagi keselamatannya. "Kata Yesus kepadanya: "Aku berkata kepadamu, sesungguhnya hari ini juga engkau akan ada bersama-sama dengan Aku di dalam Firdaus." (Lukas 23:43). Di sinilah letak arti pentingnya pendampingan mereka yang berada dalam situasi akhir hidup, ketika seorang pasien berada dalam kegelapan yang paling ngeri, ketika dia akan berhadapan dengan puncak akhir kehidupannya di dunia ini, ketika dia tidak tahu persis apa yang harus dibuat, bantuan sangat diperlukan. Bantuan ini sangat diperlukan bukan hanya bagi orang-orang sederhana, tetapi juga mereka yang beriman dan yang kuat. Semua orang membutuhkan bantuan itu.

Ketika berhadapan dengan kematian, banyak orang akan mengalami ketidak berdayaan dan kegelapan. Bahkan Yesuspun mengalami hal serupa, "Dan pada jam tiga berserulah Yesus dengan suara nyaring: "Eloi, Eloi, lama sabakhtani?", yang berarti: Allahku, Allahku, mengapa Engkau meninggalkan Aku?" (Markus 15:34).

Oleh karena itulah maka jangan pernah membiarkan mereka harus menghadapinya sendirian. Sehebat apapun juga, orang itu memerlukan bantuan orang lain. Di sini pastoral care harus menjadi teman dan penuntun ke arah yang benar. Maka pastoral care harus menjadi bagian integral dari pelayanan rumah sakit.

Secara garis besar, dalam kerangka pastoral kepada mereka yang sakit, ada banyak hal yang bisa dibuat, misalnya:

a. Health Pastoral Care (cura animarum): bantuan religius dan bantual spiritual abagi pasien dan keluarganya. 
b. Sosio Medis: membantu pasien dan keluarganya secara sosial-ekonomis, misalnya bagaimana cara mendapatkan layanan BPJS, mengusahakan dana untuk mereka yang berkekurangan.

c. Konseling Pastoral: memberikan pendampingan psikologis dan peneguhan pasien dan keluarganya dalam menghadapi penyakit dan kematian)

d. Kunjungan orang sakit

e. Pendapingan dan pastoral bagi seluruh staff rumah sakit agar visi dan misi rumah sakit Katolik tetap terjaga dan juga agar mereka mendapatkan kekayaan iman dan peneguhan di dalam pekerjaannya.

f. Dsb.

\section{Petugas Health Pastoral Care}

Sebenartnya yang bertugas untuk Health Pastoral Care adalah semua pelayan kesehatan yang bertugs dalam pelayanan kesehatan. Semua pelayan kesehatan berkewajiban untuk membagikan kekaayaan rohani dan spiritualitasnya bagi mereka yang sedang sakit dan memerlukan bantuan. Akan tetapi supaya pastoral care itu bisa menjadi effektif dan sampaui pada sasaran, maka perlu dibentuk team pastoral care yang terdiri:

a. Spiritualis yang bertigas memberikan pembinaan rohani dan konseling pastoral yang berhubungan dengan masalah rohani.

b. Imam yang biasanya diseput kapelan yang sebagai wakil Gereja bertugas untuk menerimakan sakramen sakramen yang diperlukan sesuai dengan kebutuhan.

c. Petugas sosial yang bertugas untuk membantu pasien menangani masalah-masalah sosial-administratif

d. Psikolog yang bertugas untuk memberikan konseling pastoral yang sangat berguna bagi pasien dan keluarganya.

e. Petugas lain yang diperkukan, sesuai dengan situasi dan kondisi pelayanan yang ada di rumah sakit.

\section{Cakupan pelayanan}

Cakupan pelayanan Health Pastoral Care bukan hanya berhubungan dengan pasien saja tetapi juga menyangkut seluruh pelayan kesehatan yang ada di rumah sakit, baik dokter, perawat, bidan, pharmasi, administrasi dsb. Bukan hanya bagi pasien yang dirawat di rumah sakit saja tetapi juga pasien yang ada di tempat lain, baik yang karena usianya yang lanjut ataupun keadaanya yang sakit. Sebagaimana sudah dijelaskan di atas, tugasnya meliputi pelayanan/ bantuan religius dan spiritual. Seorang pelayan pastoral care harus sadar akan pelbagai dimensi dan hak-hak fundamental pasien, misalnya untuk dijaga harkat pribadinya, dihormati kebudayaan, cara berfikirnya, nilai-nilai spiritualnya, psikososialnya dsb. Pasien memerlukan bantuan fisik, mental, spiritual dan emosinya. Pendek kata: Bantuan yang diperlukan pasien adalah bantuan holistik kemanusiaannya. Untuk itu perlu diperhatikan beberapa poin berikut ini:

a. Ketakutan dan kesendirian berhadapan dengan sakit dan kematian adalah pengalaman yang sangat tidak mengenakkan karena sering membuat menjadi krisis spiritual. Oleh karena itu, pendampingan orang lain sangat diperlukan dalam situasi ini.

b. Siapapun juga orangnya, dia akan sangat memerlukan orang lain dalam menghadapi penyakit dan ketidakberdayaannya. Lebih-lebih ketika dia berada di ambang batas ketidak berdayaannya. Oleh karena itu, jangan pernah meninggalkan orang yang akan mati sendirian.

c. Krisis spiritual ini juga bisa menyangkut "makna hidup". Ketika orang tidak lagi melihat makna hidupnya, maka krisis itu juga akan terjadi. Situasi semacam ini biasanya juga akan terjadi kepada banyak orang, khususnya bagi mereka yang terpaksa harus diopname dalam waktu yang panjang.

d. Pelayan kesehatan juga bisa mengalami pertanyaan tentang makna hidup ini, lebih-lebih kalau orang terlalu banyak pekerjaan dan kurang 
refresh terhadap hidupnya. Kesehatan spiritual dari pelayan kesehatan menjadi syarat supaya bisa bekerja dengan optimal.

e. Petugas pastoral care juga akan membantu keluarga dan pasien serta para pelayan kesehatan manakala mereka mengalami masalah-masalah etika-moral yang sukar untuk dipecahkan.

f. Petugas pastoral care juga bisa menjadi jembatan antara pasien/ keluarga dengan dokter/ pelayan kesehatan lainnya.

g. Memberikan bantuan-bantual sosialmedis yang berhubungan dengan sakit.

\section{Sakramen - sakramen bagi Orang Sakit}

Gereja memberikan perhatian istimewa bagi orang yang sakit dan akan meninggal. Ada sakramen- sakramen yang dalam keadaan sehat tidak boleh diterima (terhalang) oleh karena status keadaan berdosanya tetapi dalam keadaan gawat darurat kematian sakramen itu diperkenankan, misalnya: babtis, perkawinan, ekaristi, pengampunan dsb.

Kepada mereka yang tidak terkena halangan menerima sakramen, Gereja memberikan perhatian khusus. Pelayanan khusus itu ialah: Babtis darurat, Komuni bekal suci (viaticum), Sakramen Pengampunan Dosa dan Saramen pengurapan Orang Sakit.

a. Sakramen Babtis. Dalam keadaan darurat kematian yang sudah gawat maka semua orang (bukan hanya yang Katolik tetapi yang tidak Katolik pun juga) boleh membatis asal maksud perbuatannya sama seperti yang dimaksudkan oleh Gereja dengan (Kan.861 § 2). Dalam keadaan darurat yang boleh dibabtis adalah bayi dari pasangan Katolik, atau orang yang pernah menyatakan diri ingi menjadi Katolik baik secara langsung maupun tidak langsung. Kalau orangnya tidak pernah menyatakannya - walaupun semua anaknya Katolik - maka tidak boleh dibabtis. Caranya: Dialiri air jernih (murni) dengan ucapan rumusan Triniter, "Aku membabtis kamu Atas Nama Bapa, dan Putera, dan Roh Kudus. Amin". Ketika terjadi babtisan darurat yang dilakukan oleh selain imam, maka harus secepatnya lapor kepada pastor paroki.

b. Sakramen Rekonsiliasi. Saramen Rekonsiliasi. Kalau pasien masih sadar dan bisa berbicara, sebaiknya mereka ditawari atau dianjurkan menerima sakramen pengampunan dosa. Dalam konteks rumah sakit, tetap harus dijaga kerahasiaannya, maka perlu tempat yang cukup menjaga kerahasiaan dari pendengaran dan penglihatan orang lain. Rahasia pengampunan dosa tetap harus dijaga secara absolut, juga sesudah kematian orang yang bersangkutan. Dalam keadaan darurat, maka boleh dilakukan secara singkat apa yang menjadi syarat keabsyahan dari Sakramen Pengampunan dosa. Penitensinya sebaiknya sedemikian rupa sehingga tidak menjadi beban yang tak terpikul oleh peniten yang sudah dalam keadaan darurat.

c. Sakramen Ekaristi. Kalau keadaan memungkinkan, maka bisa dirayakan misa sebagaimana biasa. Akan tetapi dalam keadaan gawat darurat, maka diberikan Viaticum: sakramen Ekaristi (Tubuh Kristus, hosti yang sudah dikonsakrir) dapat diberikan kepada pasien. Tidak selalu perlu utuh bulat hostinya tetapi bisa secuil kecil. Kalau pasien tidak bisa menelan maka boleh dimasukkan ke dalam air sedikit dan diminumkan kepada pasien. Kadang-kadang pasien juga tidak boleh minum air, oleh karena itu pelaksanaan Viaticum harus melihat keadaan konkrit pasien.

d. Sakramen Pengurapan Orang Sakit. Kita akan membahas secara lebih panjang lebar mengenai sakramen ini sebab sakramen ini menjadi salah satu sakramen yang paling sering diberikan dan sangat erat hubungannya dengan health pastoral care. 


\section{SAKRAMEN PENGURAPAN ORANG SAKIT}

\section{Pengantar}

Sakramen pengurapan orang sakit diberikan kepada mereka yang sakit untuk memberikan kekuatan spiritual maupun fisik, khususnya bagi mereka yang menghadapi ajal. Bagi banyak orang, mungkin ini menjadi sakramenyang terakhir yang bisa dia terima. Sakramen ini didirikan oleh Yesus untuk memberikan rahmat istimewa melalui Roh Kudus bagi mereka yang menerimanya. Sakramen ini menjadi salah satu sakramen yang termasuk ke dalam "The Last Rites" (Ritus Terakhir) yang terdiri atas: Sakramen Rekonsiliasi, Komuni Bekal Suci (Viaticum yang arti hurufiahnya "Bekal Perjalanan") dan Sakramen Pengurapan Orang Sakit. Gereja menjelaskan secara Panjang Lebar m engenai Sakramen ini dalam Katekismus Gereja Katolik no 1499-1532.

\section{Sejarah}

Sejak awal, Gereja sudah mengenal; sakramen ini. Para Bapa Gereja sudah memperkenalkan peran sakramen Pengurapan orang Sakit ini. Origines (sekitar tahun 250) menulis bahwa seorang peniten Kristiani "tidaklah boleh segan untuk mengatakan dosa-dosanya kepada seorang imam Tuhan dan dari mencari pengobatan .. sebagaimana Rasul Yacobus mengatakan: 'Kalau ada seorang di antara kamu yang sakit, baiklah ia memanggil para penatua jemaat, supaya mereka mendoakan dia serta mengolesnya dengan minyak dalam nama Tuhan. Dan doa yang lahir dari iman akan menyelamatkan orang sakit itu dan Tuhan akan membangunkan dia; dan jika ia telah berbuat dosa, maka dosanya itu akan diampuni." (Homilies on Leviticus 2:4).

Uskup Serapion pada tahun 350 menulis, "Kami memohon kepadaMu ya Penyelamat bangsa manusia. Engkau yang mempunyai semua kekuatan dan keutamaan, Bapa Tuhan kami Yesus Kristus, kami mohon semoga dari surga Engkau mengirim kekuatan Putra TunggalMu yang menyembuhkan, ke atas minyak ini, sehingga mereka yang akan diurapi ... akan mendapatkan manfaat karena dibebaskan dari segala macam penyakit dan dari segala macam kelemahan badaniah ... agar mendapatkan rahmat yang besar dan pengampunan dosa." (The Sacramentary of Serapion 29:1).

St. Aphraates dari Persia sekita tahun 335, menulis pelbagai macam fungsi dari minyak suci Zaitun yang menjadi tanda dari "sakramen kehidupan yang memaluinya orang Kristiani (babtis), imam (tahbisan), Raja dan nabi disempurnakan oleh urapan minyak itu. Urapan itu menerangi kegelapan (dalam S. Penguatan), Pengurapan orang Sakit, dan oleh karena sakramennya yang kudus dapat memulihkan peniten." (Demonstratio xxiii, 3, in Graffin, "Patrol. Syriaca", vol. I, p. lv).

Dalam periode selanjutnya ditegaskan kembali dalam beberapa Konsili (Kosili Nicea tahun 325, Konsili Florence tahun 1439, Konsili Trente tahun 1545 dll.) bahwa Pengurapan Orang Sakit adalah Sakramen yang daripadanya orang beriman mendapatkan rahmat secara istimewa dalam keadaannya. Protestant tidak mengakui bahwa ini adalah sakramen, tetapi Gereja Anglican dan Ortodox mengakuinya.

\section{Nama}

Dalam sejarah Gereja, Sakramen ini mempunyai beberapa nama. Berasal dari bahasa Latin Unctio (Pengurapan) maka lahirlah kata Pengurapan Orang Sakit. Sakramen ini juga dikenal dengan nama Sakramen Minyak Suci oleh karena inti dari sakramen ini adalah pengurapan dengan Minyak Suci (zaitun). Dulu juga dikenal dengan nama Extreme Unction (Sakramen Pengurapan Terakhir). Nama ini dahulu dipakai karena sakramen ini hanya diberikan kepada orang yang sudah akan meninggal dunia sehingga menjadi sakramen (atau pengurapan) yang terakhir yang diterima oleh orang beriman. Sesudah Konsili Vatikan II, nama resminya adalah Sakramen Pengurapan Orang Sakit oleh karena sakramen ini tidak hanya diberikan kepada mereka yang akan meninggal tetapi kepada mereka yang sakit berat atau yang dalam bahaya maut. 


\section{Didirikan oleh Kristus dan Dasar Biblis}

Seperti sakramen lainnya, Sakramen Pengurapan Orang Sakit juga didirikan ioleh Kristus ketika Dia masih hidup badaniah di dunia ini. Katekismus Gereja Katolik no 1511 mengatakan bahwa Sakramen Pengurapan Orang Sakit ini didirikan oleh Kristus Tuhan kita sebagai sakramen yang benar dari Perjanjian Baru. Bisa ditilik dari Injil Markus 6: 13 dan direkomendasikan dan dipromulgasikan oleh St. Yakobus Rasul dan saudara Tuhan Yesus dalam 5: 14 15)

Dalam Injil Markus 6: 13 dikatakan, "(mereka) mengoles banyak orang sakit dengan minyak dan menyembuhkan mereka." Dalam teks ini Yesus mengutus dua belas muridNya untuk pergi berdua-dua demi mewartakan Injil. Yesus memberikan bekal dengan beberapa kuasa, misalnya untuk mengusir setan dan menyembuhkan orang sakit.

Dalam Yakobus 5: 14 - 15 dikatakan, "Kalau ada seorang di antara kamu yang sakit, baiklah ia memanggil para penatua jemaat, supaya mereka mendoakan dia serta mengolesnya dengan minyak dalam nama Tuhan. Dan doa yang lahir dari iman akan menyelamatkan orang sakit itu dan Tuhan akan membangunkan dia; dan jika ia telah berbuat dosa, maka dosanya itu akan diampuni."

\section{Perintah Menyembuhkan orang Sakit}

Dalam hidup duniawiNya, dengan pelbagai cara Yesus mewartakan Kerajaan Allah, salah satu yang cukup kentara ialah dengan menyembuhkan orang sakit. "Yesus berkeliling ke semua kota dan desa; Ia mengajar dalam rumah-rumah ibadat dan memberitakan Injil Kerajaan Sorga serta melenyapkan segala penyakit dan kelemahan." (Matius 9:35). Dalam Injil diceritakan banyak mujizat penyembuhan yang dilakukan Yesus dalam kerangka pewartaan Kerajaan Allah itu. Bahkan penyembuhan itu menjadi tanda datangnya Kerajaan Allah itu sendiri. Maka tidak mengherankan bahwa setiap kali terjadi penyembuhan fisik, aspek keselamatan itu sangat menonjol, "Teguhkanlah hatimu, hai anak-Ku, imanmu telah menyelamatkan engkau." Maka sejak saat itu sembuhlah perempuan itu." (Mateus 9:22).

Oleh karena itu, tidak heran juga bahwa sebelum Yesus naik ke surga, Ia memerintahkan para pengikutnya untuk membuat hal yang serupa yakni menyembuhkan orang sakit, akan tetapi itupun dibuatnya selalu dalam kerangka pewartaan, misalnya: Matheus 10:7 - 8 "Pergilah dan beritakanlah: Kerajaan Sorga sudah dekat. Sembuhkanlah orang sakit; bangkitkanlah orang mati; tahirkanlah orang kusta; usirlah setan-setan." Dalam bagian lain dikatakan, "Dan jikalau kamu masuk ke dalam sebuah kota dan kamu diterima di situ, makanlah apa yang dihidangkan kepadamu, dan sembuhkanlah orang-orang sakit yang ada di situ dan katakanlah kepada mereka: Kerajaan Allah sudah dekat padamu." (Lukas 10:8 - 9). Yesus juga memberikan perintah untuk mewartakan Kerajaan Allah dengan cara menyembuhkan penyakit, "Pergilah dan beritakanlah: Kerajaan Sorga sudah dekat. Sembuhkanlah orang sakit; bangkitkanlah orang mati; tahirkanlah orang kusta; usirlah setan-setan." (Mateus 10: 7 - 8). Dalam Luk. 10: 9 juga dikatakan, "sembuhkanlah orang-orang sakit yang ada di situ dan katakanlah kepada mereka: Kerajaan Allah sudah dekat padamu."

Yesus juga memberikan kekuasaan kepada para Rasul untuk menyembuhkan orang-orang sakit, "Yesus memanggil kedua belas murid-Nya dan memberi kuasa kepada mereka untuk mengusir roh-roh jahat dan untuk melenyapkan segala penyakit dan segala kelemahan." (Mateus 10:1). Bahkan Yesus mengindikasikan bahwa kemampuan untuk menyembuhkan itu adalah bukti kebenaran Injili yang mereka buat, "Tanda-tanda ini akan menyertai orang-orang yang percaya: mereka akan mengusir setan-setan demi nama-Ku... mereka akan meletakkan tangannya atas orang sakit, dan orang itu akan sembuh." (Markus 16: 17-18).

Oleh karena diperintahkan oleh Yesus untuk menyembuhkan dalam kerangka pewartaan Kerajaan Allah, maka para murid pertama pun melakukan hal yang sama. Dalam Markus 6: 13 dikatakan, "mereka 
mengusir banyak setan, dan mengoles banyak orang sakit dengan minyak dan menyembuhkan mereka." Kemampuan para murid untuk mebnyembuhkan juga dilanjutkan sesudah Yesus naik ke surga, "Tetapi Petrus berkata: "Emas dan perak tidak ada padaku, tetapi apa yang kupunyai, kuberikan kepadamu: Demi nama Yesus Kristus, orang Nazaret itu, berjalanlah!" (Kisah Para Rasul 3:6) Demikian pula selanjutnya dalam Kisah Rasul 5:14 - 16 "mereka membawa orang-orang sakit ke luar, ke jalan raya, dan membaringkannya di atas balaibalai dan tilam, supaya, apabila Petrus lewat, setidak-tidaknya bayangannya mengenai salah seorang dari mereka. Dan juga orang banyak dari kota-kota di sekitar Yerusalem datang berduyun-duyun serta membawa orang-orang yang sakit dan orang-orang yang diganggu roh jahat. Dan mereka semua disembuhkan."

Dari beberapa kutipan di atas, Nampak jelas bahwa karya penyembuhan Yesus selalu dimaksudkan lebih dari pada sekedar penyembuhan fisik tetapi lebih-lebih kesembuhan jiwa, yakni keselamatan. Oleh karena itu, setiap kali Yesus menyembuhkan orang, maka Yesus selalu bersabda, "Imanmu telah menyelamatkan kamu." Karya penyembuhan yang kelihatannya bersifat fisik itu menjangkau keseluruhan hidup manusia. Penyembuhan yang dibuat Yesus itu bersifat holistic, menyeluruh. Akan tetapi hal yang paling mendasar ialah bahwa penyembuhan penyakit itu dipakai oleh Yesus sebagai sarana pewartaan Kerajaan Allah, sarana penyelamatan manusia. Karya penyembuhan itu dibuat dalam kerangka tugasNya sebagai gembala (pastor) jiwa-jiwa. Yesus adalah gembala (pastor) yang baik (Yohanes 10: 11), yang memperhatikan kebutuhan manusia secara menyeluruh sehingga Dia memperhatikan pelbagai kebutuhan manusia. Dari hal ini maka perlulah karya Pastoral Care dalam bagian ke dua dari kursus ini.

\section{Manfaat Sakramen}

Dalam Katekismus Gereja Katolik no. 1532 dijelaskan bahwa sakramen ini secara istimewa memberikan rahmat bagi si sakit dengan:
1. Mempersatukan penderitaan si sakit dengan penderitaan Kristus demi kebaikan dia sendiri dan juga kebaikan seluruh Gereja.

2. Memberikan kekuatan, damai dan keberanian untuk menghadapi secara Kristiani segala penderitaan, penyakit dan umkur tua

3. Pengampunan dosa jika si sakit tidak bisa mendapatkan pengampunan dosa melalui Sakramen Pengampunan.

4. Pemulihan kesehatan jika ini kondusif bagi keselamatan jiwanya

5. Persiapan untuk memasuki hidup kekal

Melalui Sakramen Pengurapan Orang Sakit, Allah memberikan rahmat Roh Kudus yang memperbnaharui kepercayaan dan iman akan Allah dan memperkuat melawan pencobaan agar jangan sampai putus asa dalam penderitaan dan dalam menghadapi kematian. Dari padanya mengarah kepada penyembuhan spiritual dan pengampunan dosa. Rahmat ini mengalir dari penebusan Kristus yang wafat sebagaimana dikatakan dalam Matheus 8: 17 "Hal itu terjadi supaya genaplah firman yang disampaikan oleh nabi Yesaya: "Dialah yang memikul kelemahan kita dan menanggung penyakit kita."

Menjadi jelaslah bagi kita bahwa sakramen ini bukan khusus hanya bagi mereka yang akan meninggal, tetapi bagi setiap orang yang sudah dibabtis yang mengalami sakit parah, atau bahaya kematian atau usia tua, maka orang tersebut sebaiknya menerima sakramen ini.

\section{Sakramen Pengurapan Orang Sakit dalam KHK}

\section{Definisi}

Kan. 998 - Pengurapan orang sakit, dengannya Gereja menyerahkan kepada Tuhan yang menderita dan dimuliakan umat beriman yang sakit berbahaya, agar Ia meringankan dan menyelamatkan mereka, diberikan dengan mengurapkan minyak kepada mereka serta mengucapkan kata-kata yang ditetapkan dalam buku-buku liturgi. 


\section{Perayaan Sakramen}

Kan. 999 - Selain oleh Uskup, minyak yang dipergunakan dalam pengurapan orang sakit dapat diberkati oleh:

$1^{\circ}$ yang dalam hukum disamakan dengan Uskup diosesan;

$2^{\circ}$ dalam keadaan terpaksa, imam manapun tetapi dalam perayaan sakramen itu sendiri.

Kan. 1000 - $§ 1$. Pengurapan hendaknya dilaksanakan secara teliti dengan kata-kata, urutan dan cara yang ditetapkan dalam buku-buku liturgi; tetapi dalam keadaan terpaksa, cukuplah satu pengurapan pada dahi atau juga pada bagian lain dari tubuh, dengan mengucapkan rumus secara utuh. $\S$ 2. Pengurapan hendaknya dilakukan oleh pelayan dengan tangannya sendiri, kecuali alasan berat menganjurkan penggunaan suatu alat.

Kan. 1001 - Para gembala jiwa-jiwa dan orang-orang yang dekat dengan yang sakit hendaknya mengusahakan agar mereka yang sakit pada waktu yang tepat diringankan dengan sakramen ini.

Kan. 1002 - Perayaan bersama pengurapan orang-orang sakit, yakni untuk beberapa orang sakit bersama, yang telah dipersiapkan dan berdisposisi baik, dapat dilakukan menurut ketentuan-ketentuan Uskup diosesan.

\section{Pelayan Pengurapan Orang Sakit}

Kan. 1003 - § 1. Setiap imam dan hanya imam dapat melayani pengurapan orang sakit secara sah.

$\S 2$. Kewajiban dan hak melayani pengurapan orang sakit dimiliki oleh semua imam, yang ditugaskan untuk penggembalaan jiwa-jiwa, terhadap umat beriman yang diserahkan pada tugas pastoralnya; atas alasan yang masuk akal, setiap imam lain manapun dapat melayani sakramen itu dengan persetujuan yang sekurang-kurangnya diandaikan dari imam yang disebut diatas.

$\S 3$. Setiap imam manapun boleh membawa minyak yang diberkati, agar dalam keadaan mendesak dapat melayani sakramen pengurapan orang sakit.

\section{Orang yang Harus Diberi Pengurapan Orang Sakit}

Kan. 1004 - $§ 1$. Pengurapan orang sakit dapat diberikan kepada orang beriman yang telah dapat menggunakan akal-budi, yang mulai berada dalam bahaya karena sakit atau usia lanjut.

$\S 2$. Sakramen itu dapat diulangi, jika si sakit, setelah sembuh, jatuh sakit berat lagi, atau jika masih dalam keadaan sakit yang sama, bahayanya menjadi semakin gawat.

Kan. 1005 - Dalam keraguan apakah si sakit sudah dapat menggunakan akal-budi, atau apakah sakitnya membahayakan, atau apakah sudah mati, hendaknya sakramen itu diberikan.

Kan. 1006 - Kepada orang-orang sakit, yang sewaktu masih sadar diri memintanya sekurang-kurangnya secara implisit, hendaknya sakramen itu diberikan.

Kan. 1007 - Pengurapan orang sakit hendaknya jangan diberikan kepada mereka, yang membandel dalam dosa berat yang nyata.

\section{Beberapa Catatan Praktis}

a. Sampai kapan bisa menerima sakramen pengurapan orang Sakit? Gereja menyetujui kriteria kematian sebagaimana diusung oleh dunia kedokteran yakni: kriteria kematian batang otak. Kematian batang otak tidak terjadi serta merta dengan berhentinya paruparu dan jantung. Masih diperlukan beberapa menit (paling lama 30 menit) sesudah berhentinya nafas, tentu saja tergantung kasus dan keadaan. Kalau kita tidak tahu apakah pasien itu masih hidup atau telah mati, maka kita membela kehidupan dan berkata, "Dia masih hidup" sampai terbukti kebalikannya. Oleh karena itu kalau pasien sudah tidak bernafas 20 menit yang lalu, kita masih boleh mengadaikan bahwa dia masih hidup dan bisa menerima sakramen pengurapan orang sakit. Kasusnya berbeda kalau pasien meninggal di ICU yang dipasang alat EEG. Kalau daripantauan alat, batang 
otaknya sudah mato maka dia tidak boleh menerima sakramen pengurapan orang sakit.

b. Anak kecil yang belum bisa mempergunakan akal budinya tidak perlu diberi minyak suci karena dia masih suci dan tidak ada dosa yang harus diampuni. Akan tetapi bisa terjadi bahwa karena alasan pastoral, bisa juga diberi karena memang tidak ada larangan (bdk. Kan 1005).

Jangan menunggu pasien sampai akan mati (gawat kematian) baru memanggil pastor untuk menerimakan sakramen perminyakan. Sakramen Pengurapan orang sakit bukan hanya bagi mereka yang akan meninggal tetapi untuk orang yang sakit. Jadi: tidak usah menunggu gawat sekali baru panggil pastor untuk melayaninya.

\section{CB. Kusmaryanto}

Lulusan Program Doktoral di Pontifical Gregorian University, berkarya sebagai dosen Fakultas Teologi Universitas Sanata Dharma, Yogyakarta;

Email:kusmaryanto@gmail.com

\section{CATATAN AKHIR:}

1 John Paul II, Motu Proprio "Dolentium hominum," Feb. 11, 1985, dalam Insegnamenti VIII/1 (1985): 475.

2 John Paul II, "To the Catholic health organizations of the United States of America", tanggal 14 September 1987, dalam Insegnamenti X/3 [1987] 502-503, n. 3).

3 John Paul II, Encyclical Evangelium vitae, March 25, 1995, n. 27

4 "Your presence at the sick-bed is bound up with that of those - priests, religious and laity - who are engaged in apostolate to the sick. Quite a number of the aspects of that apostolate coincide with the problems and tasks of the service to life rendered by medicine. There is a necessary interaction between the exercise of the medical profession and pastoral work, because the one object of both is the human person, seen in his dignity of a child of God, a brother or sister needing, just like ourselves, help and comforting" (John Paul II, "To the World Congress of Catholic Doctors", Oct. 3 1982, in Insegnamenti V/3, p. 676, n. 6).

5 "You, while you alleviate sufferings and try to cure them, at the same time are witnesses of the Christian view of suffering and of the meaning of life and death, in the way it is taught by your Christian faith" (John Paul II, "To the Catholic Health Organizations of the United States of America", Sept. 14, 1987, in Insegnamenti X/3 [1987] pp. 502 and 505.)
6 JOHN PAUL II, Apost. Exhort. Christifideles laici, Dec. 30, 1988, in Insegnamenti XI/4, p. 2160, n. 53.

7 Cf. JOHN PAUL II, to the participants at the International Congress for Assistance to the Dying, in Oss. Rom. March 18, 1992, n. 6. "Every individual, precisely by reason of the mystery of the Word of God who was made flesh (cf. Jn 1: 14), is entrusted to the maternal care of the Church" JOHN PAUL II, Encyclical Evangelium vitae, March 25, 1995, n. 3).

\section{DAFTAR RUJUKAN}

John Paul II, Motu Proprio: Dolentium hominum.

John Paul II, "To the Catholic health organizations of the United States of America", tanggal 14 September 1987, dalam Insegnamenti X/3 (1987): 502503.

John Paul II, "To the World Congress of Catholic Doctors", Oct. 3 1982, dalam Insegnamenti $\mathrm{V} / 3,(1982)$ : 676.

John Paul II, "Apost. Exhort. Christifideles laici, Dec. 30, 1988”, dalam Insegnamenti XI/4, p. 2160, (1988) n. 53.

John Paul II, "To the participants at the International Congress for Assistance to the Dying", dalam L'Osservatore Romano, 18 Maret 1992. 